\section{Alfentanil sedation for cardiac catheterization of children with Fontan shunts}

Paula Rautiainen MD

\begin{abstract}
After Fontan operation, prolonged invasive cardiac assessment is often needed. This study is a clinical evaluation of the effectiveness of flunitrazepam premedication, EMLA ${ }^{\otimes}$ cream, and alfentanil continuous infusion for management of children undergoing such catheterization. Fourteen consecutive subjects aged 5-20 yr with Fontan shunts (right atrium to pulmonary artery) undergoing elective haemodynamic and electrophysiological catheterization were sedated with an individually titrated alfentanil infusion. After oral premedication with flunitrazepam $2 \mathrm{mg}$, the mean induction dose and mean maintenance requirement of alfentanil were $4.4 \pm 2.7 \mu \mathrm{g} \cdot \mathrm{kg}^{-1}$ and $10.3 \pm 8.6$ $\mu \mathrm{g} \cdot \mathrm{kg}^{-1} \cdot \mathrm{hr}^{-1}$, respectively. Mean oxygen consumption during haemodynamic catheterization was $4.1 \pm 0.4 \mathrm{ml} \cdot \mathrm{kg}^{-1} \cdot \mathrm{min}^{-1}$ with an average individual variation of $10 \%$. For every patient, tranquil and stable conditions during catheterization could be produced. It is concluded that alfentanil infusion is a method of sedation of children and adolescents with Fontan shunts during haemodynamic and electrophysiologic catheterization. However, continuous monitoring of ventilation and an understanding of the slow circulation time after Fontan operation are essential with such sedation in these patients.
\end{abstract}

Après une opération de Fontan, l'installation d'un monitorage cardiaque invasif nécessite souvent beaucoup de temps. Cette étude est une évaluation clinique de l'efficacité d'une prémédi-

\section{Key words}

ANAESTHESIA: paediatric;

ANAESTHETIC TECHNIQUES: intravenous;

ANAESTHETICS, INTRAVENOUS: alfentanil;

HEART: catheterization;

METABOLISM: oxygen consumption.

From the Department of Anaesthesiology, Children's Hospital, University of Helsinki, SF-00290 Helsinki, Finland

Address correspondence to: Dr. Paula Rautiainen,

Children's Hospital, University of Helsinki, SF-00290

Helsinki, Finland.

Accepted for publication 1st July, 1992. cation au flunitrazépam, de la crème $E M L A^{\circledR}$ et d'une infusion continue d'alfentanil pour la prise en charge de patients soumis à un tel cathétérisme. Quatorze sujets âgés de 5 à 20 ans porteurs d'un shunt de Fontan (oreillette droite vers artère pulmonaire) programmés pour un cathétérisme hémodynamique et électrophysiologique ont reçu une sédation avec une infusion d'alfentanil titrée individuellement. Après une prémédication orale au flunitrazépam $2 \mathrm{mg}$, la dose moyenne d'induction puis d'entretien d'alfentanil a été de 4, $4 \pm 2,7 \mu \mathrm{g} \cdot \mathrm{kg}^{-1}$ et de 10,3 $\pm 8,6 \mu \mathrm{g} \cdot \mathrm{kg} \cdot \mathrm{hr} \mathrm{r}^{-1}$ respectivement. La consommation moyenne d'oxygène pendant le cathétérisme hémodynamique a été de 4,1 $\pm 0,4 \mathrm{ml} \cdot \mathrm{kg} \cdot \mathrm{min}^{-1}$ avec une variation individuelle moyenne de $10 \%$. En conclusion, on a procuré pour chaque patient des conditions tranquilles et stables pendant le cathétérisme. Néanmoins, un monitorage continu de la ventilation ainsi que la notion de l'existence d'un temps de circulation prolongé après une intervention de Fontan sont essentielles pour une telle sédation chez ces patients.

Although not a very painful procedure, haemodynamic and electrophysiological catheterization demands that the patient stay tranquil and resting during the lengthy investigation in order to get proper information on the heart and circulation. Cardiac catheterization has been considered as one of the most traumatic experiences in young adults with congenital heart disease. ${ }^{1}$ Children require sedation for these investigations. ${ }^{2}$ There are few guidelines for paediatric sedation in the cardiac laboratory and a lytic MPC(meperidine-, promethazine- and chlorpromazine-) combination is usually recommended. This cocktail has many cardiovascular side effects. ${ }^{3}$ Alfentanil is an opioid analgesic with rapid onset and a short duration of action providing cardiovascular stability during anaesthesia. ${ }^{4}$ It has been administered as a continuous infusion to sedate successfully small children and infants for cardiac catheterization. ${ }^{5}$ The Fontan operation is a right atrium to pulmonary artery connection for patients with congenital tricuspid atresia, or univentricular atrioventricular connection. Patients with Fontan shunt often need invasive evaluation of the cardiopulmonary status. The lack of the pumping ventricle for the venous return causes a slow circulation in these 
patients. Furthermore, it is essential to prevent increase of pulmonary vascular resistance. ${ }^{6,7}$ There are no recommendations of how to sedate Fontan patients. With the earlier good experience of alfentanil sedation in small cardiac children, ${ }^{5}$ and with the known cardiovascular stability of alfentanil, the present study was undertaken to find guidelines for the anaesthetic management, using alfentanil, of children and adolescents with Fontan shunts during haemodynamic and electrophysiological catheterization.

\section{Methods}

After Institutional Ethics Committee approval, 14 consecutive children or adolescents with Fontan shunts, whose parents gave informed consent, were studied during elective haemodynamic and electrophysiological catheterization. Only patients with normal or slightly decreased diffusing capacity and respiratory function tests were included. Those with chromosome anomalies or renal or hepatic disease were excluded.

EMLA $^{\circledR}$ cream was applied to the groins and hands two hours before the patient arrived at the cardiac laboratory. One hour after premedication with flunitrazepam $2 \mathrm{mg}$ orally, an iv cannula was inserted in the hand, and Ringer's lactate was infused at a rate of $4 \mathrm{ml} \cdot \mathrm{kg}^{-1} \cdot \mathrm{hr}^{-1}$. The groins were infiltrated with $1 \%$ lidocaine for femoral vascular approach.

The ECG, heart rate, arterial oxygen saturation (Biox 3700, Ohmeda) and end-tidal carbon dioxide (Normocap, Datex) were monitored continuously. End-tidal $\mathrm{PCO}_{2}$ was sampled via an adaptor located $5 \mathrm{~mm}$ inside the nostril by using a continuous flow of $200 \mathrm{ml} \cdot \mathrm{min}^{-1}$. Noninvasive blood pressure (Dinamap, Criticon) was recorded every five minutes. An arterial sample for blood gas analysis was drawn during stable sedation with simultaneous $\mathrm{PETCO}_{2}$ documentation. During haemodynamic catheterization, patients breathed room air because oxygen consumption could not be measured with supplementary oxygen. ${ }^{8}$ Otherwise, they breathed $30 \%$ oxygen in air spontaneously via a transparent face mask. Ventilation was assisted manually if the patient became apnoeic for more than $15 \mathrm{sec}$.

Alfentanil was administered under the following dosage guidelines. It was not given until the patient expressed discomfort, restlessness or pain. Thereafter, patients were sedated with repeated $i v$ alfentanil increments of 2-4 $\mu \mathrm{g} \cdot \mathrm{kg}^{-1}$ every two to three minutes until satisfactory sedation was reached. After induction, an infusion of alfentanil $10 \mu \mathrm{g} \cdot \mathrm{kg}^{-1} \cdot \mathrm{hr}^{-1}$ was started to maintain a satisfactory level of sedation. This dose was chosen according to a previous pilot study. If sedation was regarded as unsatisfactory, an incremental dose of alfentanil, $2-4 \mu \mathrm{g} \cdot \mathrm{kg}^{-1}$, was given and the infusion was increased by $2-3 \mu \mathrm{g} \cdot \mathrm{kg}^{-1} \cdot \mathrm{hr}^{-1}$. If sedation was considered to be too deep, the infusion was decreased by $2-3$ $\mu \mathrm{g} \cdot \mathrm{kg}^{-1} \cdot \mathrm{hr}^{-1}$.

The quality of sedation was assessed continuously by the anaesthetist. During satisfactory sedation, the patient was allowed to be awake, drowsy or sleepy; however, he should tolerate the supine position and stay calm and resting. Sedation was regarded as unsatisfactory if the patient complained of pain or discomfort, or was restless or moved extremities. Sedation was too deep if the patient did not respond to command or shoulder tap for ten minutes.

Haemodynamic catheterization consisted of arterial and venous cannulations, as well as of shunt and pressure recordings with continuous oxygen consumption measurement. Oxygen consumption was measured by indirect calorimetry and registered every minute (Deltatrac, Datex). Cardiac index was measured by thermodilution method (cardiac output computer COM-1, Edwards Laboratories). For electrophysiological purposes, sinus node function as well as sinoatrial and atrioventricular conduction were assessed by catheters inserted into the right atrium and the left ventricle. Angiography of the right atrium and the systemic chamber was performed.

After investigations, patients stayed in the recovery room until the pressure bandages could be removed from the groins and they were fully cooperative. Thereafter, they were allowed to drink and eat without restriction. Nausea and difficulties with voiding were registered on the perioperative day.

Individual induction doses and maintenance requirements of alfentanil were calculated. The maintenance dose was the cumulative total dose after the induction period given during sedation. Variations of individual oxygen consumption as well as of blood pressure and heart rate during the study were evaluated for every patient by dividing standard deviation (SD) of individual oxygen consumption and of individual blood pressure and heart rate readings by their mean values (electrophysiological investigation period was excluded due to variable induced pacing rhythms). Mean values $\pm S D$ are shown. Best fit reggression analysis was used to test the correlation between the age of the patient and the induction dose of alfentanil.

\section{Results}

Patient characteristics are presented in the Table. The mean age of the patients was $11.3 \pm 4.2 \mathrm{yr}$, and the mean time after Fontan operation was $4.7 \pm 1.9$ yr. All were ASA physical status II or III. The mean durations of catheterization and sedation were $4.2 \pm 0.7$ and $3.7 \pm 1.2$ hr, respectively.

Mean induction dose of alfentanil was $4.4 \pm 2.7$ 
TABLE Patient data

\begin{tabular}{|c|c|c|c|c|c|}
\hline$\#$ & Age yr & $\begin{array}{l}\text { Age at Fontan } \\
\text { operation yr }\end{array}$ & Weight kg & Diagnosis & Medication \\
\hline 1 & 5.8 & 3.7 & 23.5 & $\mathrm{TA}+\mathrm{PA}+\mathrm{UVH}$ & $D, F, P, E$ \\
\hline 2 & 6.1 & 4.3 & 19.4 & $\mathrm{TA}+\mathrm{UVH}$ & $\mathrm{D}, \mathrm{Di}, \mathrm{W}$ \\
\hline 3 & 6.7 & 3.6 & 20.8 & UVH & - \\
\hline 4 & 6.9 & 2.9 & 22.0 & TA & $D, F$ \\
\hline 5 & 9.3 & 6.1 & 30.0 & $\mathrm{TA}+\mathrm{PS}+\mathrm{UVH}+\mathrm{TGA}$ & - \\
\hline 6 & 10.8 & 6.5 & 27.5 & TA & $\mathrm{D}$ \\
\hline 7 & 12.2 & 6.7 & 33.6 & $\mathrm{DILV}+\mathrm{UVH}+\mathrm{TGA}$ & $\mathrm{D}, \mathrm{F}, \mathrm{P}$ \\
\hline 8 & 12.5 & 6.3 & 40.0 & TA & $\mathrm{D}$ \\
\hline 9 & 12.5 & 6.4 & 32.5 & TA+UVH & - \\
\hline 10 & 12.6 & 6.6 & 33.0 & $\mathrm{DILV}+\mathrm{UVH}+\mathrm{TGA}$ & $\mathrm{D}$ \\
\hline 11 & 12.8 & 8.8 & 34.0 & DILV+UVH+TGA & - \\
\hline 12 & 13.0 & 7.2 & 33.0 & $\mathrm{DORV}+\mathrm{UVH}+\mathrm{TGA}$ & $\mathrm{D}, \mathrm{F}$ \\
\hline 13 & 16.6 & 7.8 & 63.5 & $\mathrm{TA}+\mathrm{PS}+\mathrm{UVH}$ & $\mathrm{D}$ \\
\hline 14 & 20.8 & 15.6 & 67.0 & TA+UVH & - \\
\hline
\end{tabular}

Abbreviations: $\mathrm{DILV}=$ double inlet left ventricle; $\mathrm{DORV}=$ double outlet right ventricle; $\mathrm{PA}=$ pulmonary atresia; $\mathrm{PS}=$ pulmonary stenosis; $\mathrm{TA}=$ tricuspid atresia; $\mathrm{TGA}=$ transposition of great arteries; $\mathrm{UVH}=$ univentricular heart. Medication: $\mathrm{D}=$ digoxin; $\mathrm{Di}=$ disopyramide; $\mathrm{F}=$ furosemide; $\mathrm{E}=$ enalapril; $\mathrm{P}=$ pratsosin; $\mathrm{W}=$ warfarin.

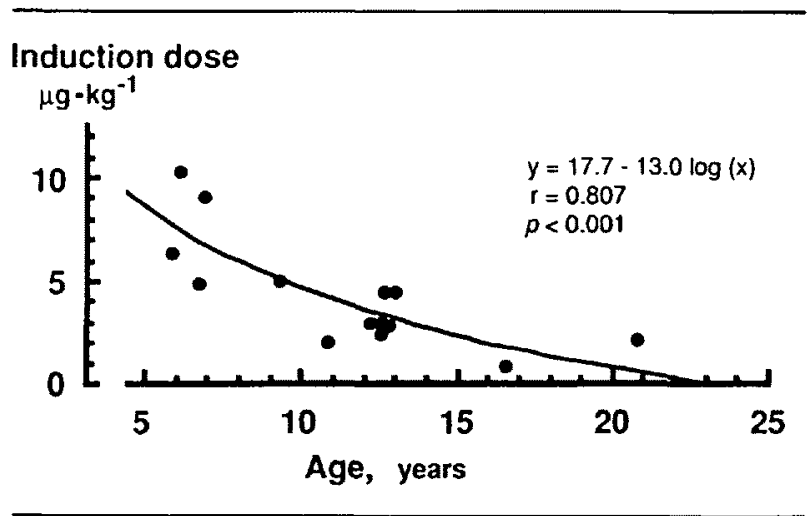

FIGURE Correlation between an intravenous induction dose of alfentanil and patient's age in children sedated for haemodynamic and electrophysiological catheterization. Patients were premedicated with oral flunitrazepam.

$\mu \mathrm{g} \cdot \mathrm{kg}^{-1}$ and the mean maintenance requirement $10.3 \pm$ $8.6 \mu \mathrm{g} \cdot \mathrm{kg}^{-1} \cdot \mathrm{hr}^{-1}$. During the whole sedation, the mean interval between additional increments of alfentanil was $1.5 \mathrm{hr}$, and between infusion rate changes was $0.9 \mathrm{hr}$. A correlation existed between an individual induction dose and the age of the patient: induction dose $\left(\mu \mathrm{g} \cdot \mathrm{kg}^{-1}\right)=17.7$ $-13.0 \cdot \log$ age $(\mathrm{yr})(\mathrm{r}=0.807), P<0.001$ (Figure).

Cardiac measurements were as follows. The mean blood pressure and heart rate were $108 / 64 \mathrm{mmHg}(14.4 / 8.5 \mathrm{kPa})$ and 69 beats $\cdot \mathrm{min}^{-1}$, respectively. Mean individual variations of these variables during catheterization were $7 \%$ for systolic arterial pressure and $10 \%$ for both diastolic arterial pressure and heart rate. Mean values for right atrial pressure, pulmonary capillary wedge pressure, and left ventricular end diastolic pressure were $13 \pm 4 \mathrm{mmHg}$ (1.8 $\pm 0.6 \mathrm{kPa}), 7 \pm 3 \mathrm{mmHg}(0.9 \pm 0.4 \mathrm{kPa})$ and $6 \pm 2$ $\mathrm{mmHg}(0.8 \pm 0.3 \mathrm{kPa})$, respectively. Mean cardiac index was $2.2 \pm 0.6 \mathrm{~L} \cdot \mathrm{min}^{-1} \cdot \mathrm{m}^{-2}$.

The mean oxygen consumption during cardiac catheterization was $4.1 \pm 0.4 \mathrm{ml} \cdot \mathrm{kg}^{-1} \cdot \mathrm{min}^{-1}$ with an average individual variation of $10 \%$. The mean arterial $\mathrm{pH}$ and $\mathrm{PCO}_{2}$ were $7.37 \pm 0.05$ and $42 \pm 6 \mathrm{mmHg}$ ( $5.6 \pm 0.8$ $\mathrm{kPa}$ ), respectively. The mean value of the simultaneously documented $\mathrm{PETCO}_{2}$ was $41 \mathrm{mmHg}(5.5 \mathrm{kPa})$, which was $98 \%$ of $\mathrm{PaCO}_{2}$.

Ventilation was assisted once due to apnoea. Breathing of patient \#4 was manually assisted for three minutes immediately after induction of anaesthesia and the decrease of saturation to $74 \%$ was rapidly returned to normal. Patient \#3 complained of nausea $3.5 \mathrm{hr}$ after induction of sedation during investigation when the paced heart rate had been increased to 210 beats $\cdot \mathrm{min}^{-1}$. Despite administration of droperidol $10 \mu \mathrm{g} \cdot \mathrm{kg}^{-1} \mathrm{iv}$, this patient vomited once during catheterization, and twice during the recovery room period. No signs of aspiration, cough or breathing difficulties were noticed. Every patient started drinking or eating within a few hours postoperatively. No difficulties in voiding were found.

\section{Discussion}

We evaluated prospectively the use of alfentanil continuous infusion in combination with oral flunitrazepam and EMLA $^{\circledR}$ cream for sedation of children and adolescents undergoing cardiac catheterization. All the patients had a Fontan shunt in place. Although cardiac catheterization is not very painful, patients must remain immobilized for a prolonged period of time, and we found that oral flunitra- 
zepam was insufficient when combined only with EMLA ${ }^{(1)}$ cream. With alfentanil infusion, we were able to provide adequate sedation and analgesia.

Induction and maintenance doses of alfentanil in the present study ( $4 \mu \mathrm{g} \cdot \mathrm{kg}^{-1}$ and $10 \mu \mathrm{g} \cdot \mathrm{kg}^{-1} \cdot \mathrm{hr}^{-1}$, respectively) were less than those needed for surgical anaesthesia (75-150 $\mu \mathrm{g} \cdot \mathrm{kg}^{-1}$ and $25-300 \mu \mathrm{g} \cdot \mathrm{kg}^{-1} \cdot \mathrm{hr}^{-1}$ ). ${ }^{9.10}$ These differences are explained by different degrees of noxious stimulation. The present doses were also less than reported earlier for cardiac catheterization in children younger than two years of age who required $20 \mu \mathrm{g} \cdot \mathrm{kg}^{-1}$ and 30 $\mu \mathrm{g} \cdot \mathrm{kg}^{-1} \cdot \mathrm{hr}^{-1}$ for induction and maintainance of anaesthesia, respectively. ${ }^{5,11}$ Older children and adolescents are more cooperative and capable of understanding the activity limitations during the procedure. This is corroborated by the present finding of the smaller induction dose the older the patient became. Thus, there is no need for profound sedation among older paediatric patients. From a clinical point of view, the present infusion method is practical.

Oxygen consumption in children has been found to decrease by $25-43 \%$ after sedation with an oral MPCcocktail. ${ }^{12}$ In a paediatric physical exercise study where the bicycle ergometer protocol consisted of gradual increase of workload from rest up to a maximum of 120 watts, oxygen consumption increased by over $200 \% .{ }^{13}$ In the present study, the level of sedation was assessed continuously by the anaesthetist. Satisfactory stability in sedation can be considered to have been reached as the individual variation of oxygen consumption was only $10 \%$ during catheterization. Oxygen consumption could not be monitored during electrophysiological investigation since indirect calorimetry method functions only in room air, and to guarantee enough oxygen delivery to tissues during paced high cardiac rates it is safer when the patient breathes oxygen-rich air.

Although respiratory depression is a common side effect of opioid, ${ }^{14}$ normal arterial $\mathrm{PCO}_{2}$ and $\mathrm{pH}$ could be maintained during stable sedation. End-tidal $\mathrm{PCO}_{2}$ monitoring was shown to be a reliable method for assessing adequate ventilation in these spontaneously breathing patients. Furthermore, the mean partial pressure of the end-tidal carbon dioxide was $98 \%$ of the simultaneously documented partial pressure in the arterial blood. This reliability had been documented earlier in small acyanotic, spontaneously breathing children," and in children during mechanical ventilation. ${ }^{15}$ Recognition of apnoea or hypoventilation periods is rapid when end-tidal $\mathrm{PCO}_{2}$ is monitored continuously. In the present study, one patient became apnoeic after alfentanil increments at the induction of sedation. Although titrated carefully with small boluses, breath-holding was evident. High central venous pressure of this Fontan operated child $(21 \mathrm{mmHg} / 2.8 \mathrm{kPa})$ suggests a slow venous circulation time and a need of even longer than two- to three-minute intervals between alfentanil boluses during induction to assess properly the peak effect of the dose. In adults, an induction dose of alfentanil was recently recommended to be given as a slow intravenous infusion to avoid apnoea. ${ }^{16}$

In conclusion, alfentanil infusion sedation after flunitrazepam premedication provides tranquil circumstances for both the patient and the cardiologist during haemodynamic and electrophysiological catheterization. Dosage recommendations of alfentanil are as increments of $2 \mu \mathrm{g} \cdot \mathrm{kg}^{-1}$ every two to three minutes for induction, and as an infusion of $10 \mu \mathrm{g} \cdot \mathrm{kg}^{-1} \cdot \mathrm{hr}^{-1}$ for maintenance of sedation. However, close monitoring of ventilation especially with end-tidal carbon dioxide recording is essential. Slow venous blood flow due to lack of a pumping chamber in the right heart in the Fontan operated patients must also be taken into account.

\section{References}

1 Doucet $S$. The young adult's perceptions of the effect of congenital heart disease on his lifestyle. Nurse Practitioner 1981; 13: 3-16.

2 Gillette PC, Ross BA, Zeigler V, Buckles D, Harold M. Electrophysiology studies. In: Garson A Jr, Brickler JT, MacNamara DG (Eds.). The Science and Practice of Pediatric Cardiology, Philadelphia: Lea \& Febiger, 1990; 3: 1744 .

3 Nahata MC, Clotz MA, Krogg EA. Adverse effects of meperidine, promethazine, and chlorpromazine for sedation in pediatric patients. Clin Pediatr 1985;24: 10 , 558-60.

4 den Hollander JM, Hennis PJ, Burm AGL, Bovill JG. Alfentanil in infants and children with congenital heart defects. Journal of Cardiothoracic Anesthesia 1988; 2: 12-7.

5 Rautiainen $P$. Alfentanil infusion for sedation in infants and small children during cardiac catheterization. Can J Anaesth 1991; 38: 980-4.

6 Laks $H$, Milliken JC, Perloff $J K$, et al. Experience with the Fontan procedure. J Thorac Cardiovasc Surg 1984; 88: 939-51.

7 Fyman PN, Goodman K, Casthely PA, Griepp RB, Ergin $M A$, Smith $P$. Anesthetic management of patients undergoing Fontan procedure. Anesth Analg 1986; 65: 516-9.

8 Deltatrac MBM-100 operator's manual. Helsinki: Datex Instrumentarium Corp., 1987; November: 23.

9 Nilsson A, Persson MP, Hartvig P. Effects of the benzodiazepine antagonist flumazenil on postoperative performance following total intravenous anaesthesia with midazolam and alfentanil. Acta Anaesthesiol Scand 1988; 32: 441-6.

10 Ausems ME, Hug CC Jr, Stanski DR, Burm AGL. Plasma concentrations of alfentanil required to supplement nitrous 
oxide anesthesia for general surgery. Anesthesiology 1986; 65: 362-73.

11 Meretoja $O A$, Rautiainen $P$. Alfentanil and fentanyl sedation in infants and small children during cardiac catheterization. Can J Anaesth 1990; 37: 624-8.

12 Baum D, Brown AC, Church SC. Effect of sedation on oxygen consumption of children undergoing cardiac catheterization. Pediatrics 1967; 39: 891-5.

13 Yabek SM, Werniy J, Chick TW, Berman WJr, McWilliams $B$. Rate-adaptive cardiac pacing in children using a minute ventilation biosensor. PACE 1990; 13: 2108-12.

14 Jaffe $J H$, Martin WR. Opioid analgesics and antagonists. In: Goodman Gilman A, Rall TW, Nies AS, Taylor P (Eds.). Goodman and Gilman's The Pharmacological Basis of Therapeutics, 8th ed., New York: Pergamon Press, 1990: 485-521.

15 Fletcher $R$. The relationship between the arterial to endtidal $\mathrm{PCO}_{2}$ difference and hemoglobin saturation in patients with congenital heart disease. Anesthesiology 1991; 75: 210-6.

16 Camu $F$, Debucquoy $F$. Alfentanil infusion for postoperative pain: a comparison of epidural and intravenous routes. Anesthesiology 1991; 75: 171-8. 